\title{
Accurate measurements of carbon monoxide in humid air using the cavity ring-down spectroscopy (CRDS) technique
}

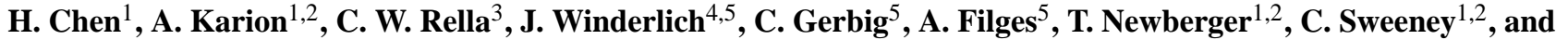 \\ P. P. Tans ${ }^{1}$ \\ ${ }^{1}$ NOAA Earth System Research Laboratory, Boulder, CO 80305, USA \\ ${ }^{2}$ Cooperative Institute for Research in Environmental Sciences, University of Colorado, Boulder, CO, USA \\ ${ }^{3}$ Picarro, Inc., Santa Clara, CA, USA \\ ${ }^{4}$ Max Planck Institute for Chemistry, Mainz, Germany \\ ${ }^{5}$ Max Planck Institute for Biogeochemistry, Jena, Germany
}

Correspondence to: H. Chen (huilin.chen@ noaa.gov)

Received: 17 August 2012 - Published in Atmos. Meas. Tech. Discuss.: 7 September 2012

Revised: 13 March 2013 - Accepted: 22 March 2013 - Published: 17 April 2013

\begin{abstract}
Accurate measurements of carbon monoxide (CO) in humid air have been made using the cavity ring-down spectroscopy (CRDS) technique. The measurements of $\mathrm{CO}$ mole fractions are determined from the strength of its spectral absorption in the near-infrared region $(\sim 1.57 \mu \mathrm{m})$ after removing interferences from adjacent carbon dioxide $\left(\mathrm{CO}_{2}\right)$ and water vapor $\left(\mathrm{H}_{2} \mathrm{O}\right)$ absorption lines. Water correction functions that account for the dilution and pressurebroadening effects as well as absorption line interferences from adjacent $\mathrm{CO}_{2}$ and $\mathrm{H}_{2} \mathrm{O}$ lines have been derived for $\mathrm{CO}_{2}$ mole fractions between 360-390 ppm and for reported $\mathrm{H}_{2} \mathrm{O}$ mole fractions between $0-4 \%$. The line interference corrections are independent of $\mathrm{CO}$ mole fractions. The dependence of the line interference correction on $\mathrm{CO}_{2}$ abundance is estimated to be approximately $-0.3 \mathrm{ppb} / 100 \mathrm{ppm}$ $\mathrm{CO}_{2}$ for dry mole fractions of $\mathrm{CO}$. Comparisons of water correction functions from different analyzers of the same type show significant differences, making it necessary to perform instrument-specific water tests for each individual analyzer. The CRDS analyzer was flown on an aircraft in Alaska from April to November in 2011, and the accuracy of the $\mathrm{CO}$ measurements by the CRDS analyzer has been validated against discrete NOAA/ESRL flask sample measurements made on board the same aircraft, with a mean difference between integrated in situ and flask measurements of $-0.6 \mathrm{ppb}$ and a standard deviation of $2.8 \mathrm{ppb}$. Preliminary testing of CRDS instrumentation that employs improved spectroscopic model functions for $\mathrm{CO}_{2}, \mathrm{H}_{2} \mathrm{O}$, and $\mathrm{CO}$ to fit
\end{abstract}

the raw spectral data (available since the beginning of 2012) indicates a smaller water vapor dependence than the models discussed here, but more work is necessary to fully validate the performance. The CRDS technique provides an accurate and low-maintenance method of monitoring the atmospheric dry mole fractions of $\mathrm{CO}$ in humid air streams.

\section{Introduction}

Atmospheric carbon monoxide (CO) plays an important role in tropospheric chemistry (Logan et al., 1981), and acts as a useful tracer for emissions of $\mathrm{CO}_{2}, \mathrm{CH}_{4}$, and $\mathrm{H}_{2}$ from biomass and fossil fuel burning (Andreae and Merlet, 2001; Levin and Karstens, 2007; Ehhalt and Rohrer, 2009; Turnbull et al., 2009). A considerable number of techniques have been employed to perform atmospheric measurements of $\mathrm{CO}$, such as nondispersive infrared spectroscopy (NDIR) (Dickerson and Delany, 1988), vacuum ultraviolet resonance fluorescence (VURF) (Gerbig et al., 1999), tunable diode laser absorption spectroscopy (TDLAS) (Sachse et al., 1987), closed path Fourier transform infrared (FTIR) absorption (Griffith et al., 2012), gas chromatography combined with a mercuric oxide detector or a flame ionization detector $(\mathrm{GC} / \mathrm{HgO}$ or GC/FID) (Novelli, 1999) and, more recently, quantum cascade laser (QCL) (McManus et al., 2008), integrated cavity output spectroscopy (ICOS) (O’Keefe, 1998), and cavity ring-down spectroscopy (CRDS) (Crosson, 2008). 

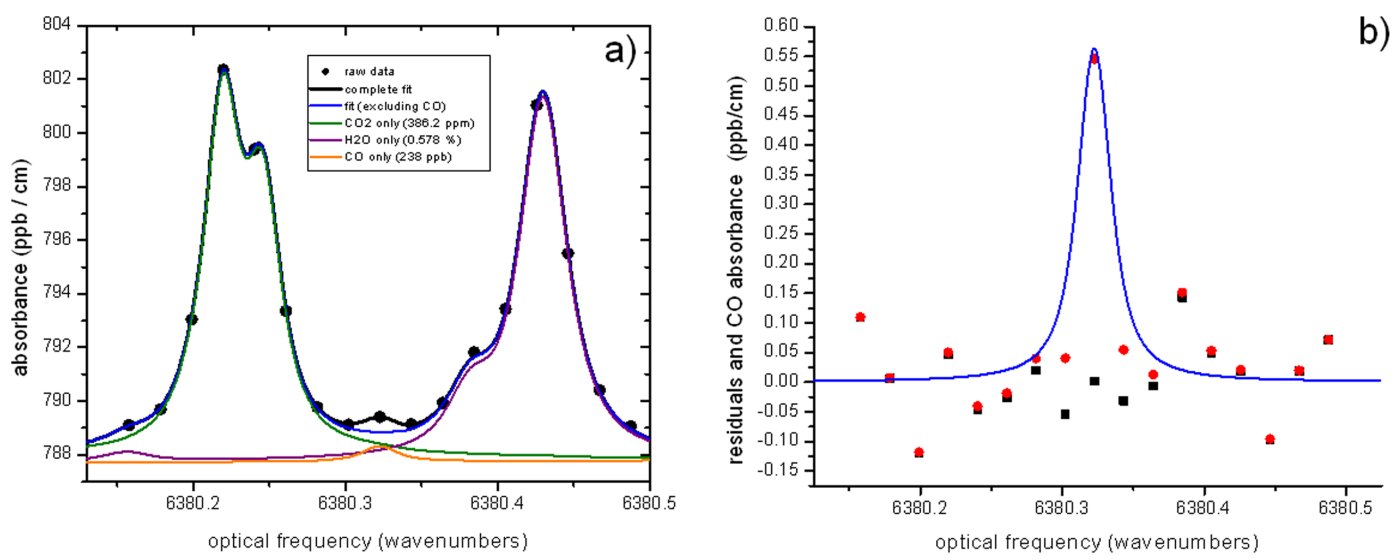

Fig. 1. The spectroscopic data and fits of $\mathrm{CO}$ and adjacent absorptions of $\mathrm{CO}_{2}$ and $\mathrm{H}_{2} \mathrm{O}$ : (a) the spectral fits of absorption data (black solid dots) for $\mathrm{CO}_{2}$ (four overlapping lines) only, $\mathrm{H}_{2} \mathrm{O}$ (three lines) only, $\mathrm{CO}$ only, excluding $\mathrm{CO}$, and all data; (b) the residuals of a multicomponent fit to the data in the left panel, with $\mathrm{CO}$ included in the fit (black solid squares), and with CO not included (red solid dots), along with the $\mathrm{CO}$ spectral fit (blue curve).

Comprehensive comparisons of measurements made using these techniques are given by Zellweger et al. (2009 and 2012). Because variations of water vapor in the atmosphere modify the mole fractions of $\mathrm{CO}$ (known as the dilution effect), sample air has always been dried in previous techniques to obtain dry air mole fractions. A major advantage of some recently available techniques (QCL/ICOS/CRDS) is that water vapor mole fractions can be simultaneously measured. This makes measurements of $\mathrm{CO}$ in humid air feasible as the $\mathrm{H}_{2} \mathrm{O}$ values can be used to correct for dilution and potential spectroscopic effects. Zellweger et al. (2012) have derived water corrections for the QCL and ICOS analyzers, but not for the CRDS analyzer due to the fact that the more complicated nature of the spectral interference requires more complicated interference testing and analysis procedures. Carbon monoxide is detected by QCL or ICOS in the mid-infrared region where the $\mathrm{CO}$ absorption is well separated from other absorption features; in contrast, the CRDS technique measures $\mathrm{CO}$ in the near-infrared region $(\sim 1.57 \mu \mathrm{m})$ where there are significant interferences from adjacent absorption lines of $\mathrm{CO}_{2}$ and $\mathrm{H}_{2} \mathrm{O}$ at ambient mole fractions of $\mathrm{CO}, \mathrm{CO}_{2}$, and $\mathrm{H}_{2} \mathrm{O}$. An example of the spectral absorptions for typical ambient mole fractions of $\mathrm{CO}(238 \mathrm{ppb}), \mathrm{CO}_{2}$ (386.2 ppm), and $\mathrm{H}_{2} \mathrm{O}(0.578 \%)$ is given in Fig. 1a. In the scanned spectral region of the $\mathrm{CO}$ absorption line, there are four $\mathrm{CO}_{2}$ absorption lines and three $\mathrm{H}_{2} \mathrm{O}$ absorption lines. The ratios of the largest line for each species in the scanned spectral region are $1: 23: 22$ for $\mathrm{CO}: \mathrm{CO}_{2}: \mathrm{H}_{2} \mathrm{O}$. For each raw spectrum (collected every few seconds), the absorption lines of $\mathrm{CO}, \mathrm{CO}_{2}$, and $\mathrm{H}_{2} \mathrm{O}$ are fit using a Levenberg-Marquardt optimization algorithm with a Galatry profile for CO (Varghese and Hanson, 1984) and a composite, empirically derived spectral profile for $\mathrm{CO}_{2}$ and $\mathrm{H}_{2} \mathrm{O}$. The mole fraction of $\mathrm{CO}$ is determined from the peak height of the $\mathrm{CO}$ spectral component (see Fig. 1b). Although it is challenging to get precise measurements of $\mathrm{CO}$ in the near-infrared region using the CRDS technique, a big advantage is that this technique employs reliable, cheap, and stable infrared lasers rather than expensive quantum cascade lasers, and the same apparatus can also be employed to measure both $\mathrm{CO}_{2}$ and $\mathrm{CH}_{4}$ precisely. In fact, $\mathrm{CRDS}$ analyzers that measure $\mathrm{CO}_{2} / \mathrm{CH}_{4} / \mathrm{CO} / \mathrm{H}_{2} \mathrm{O}$ or $\mathrm{CO}_{2} / \mathrm{CO} / \mathrm{H}_{2} \mathrm{O}$ (Picarro, Inc., Santa Clara, CA, USA, the G2401 or G2302 series) in one unit are commercially available. Extensive efforts have been carried out to make accurate measurements of $\mathrm{CO}_{2}$ and $\mathrm{CH}_{4}$ possible without drying the sample air (Chen et al., 2010; Winderlich et al., 2010; Nara et al., 2012; Rella et al., 2013). It is therefore beneficial to be able to accurately measure $\mathrm{CO}$ in humid air with the same analyzer as well.

In this paper, we derive water correction functions for the CO measurements made by the Picarro CRDS technique to account for the dilution and spectroscopic effects. In Sect. 2, we present the results from a series of laboratory experiments that are then used to derive the water correction functions. The comparison of water correction functions for $\mathrm{CO}$ from different CRDS analyzers is given in Sect. 3. The field comparison between in situ and flask measurements on board an aircraft is shown in Sect. 4. In the final section, we present the discussion and conclusion.

\section{Water correction functions for $\mathrm{CO}$ measurements}

Mole fractions of $\mathrm{CO}$ and other trace gases are influenced significantly by variations of water vapor in the atmosphere. For this reason, atmospheric $\mathrm{CO}$ measurements need to be reported as mole fractions in dry air. In principle, there is a simple linear relationship between the $\mathrm{CO}$ mole fraction in wet air $\left(\mathrm{CO}_{\text {wet }}\right)$ and in dry air $\left(\mathrm{CO}_{\text {dry }}\right)$ if only the water vapor dilution effect is considered: 
Table 1. Summary of water tests for CO on a series of Picarro CRDS analyzers.

\begin{tabular}{llllll}
\hline Group & Model & Analyzer S/N & $\mathrm{CO}(\mathrm{ppb})$ & $\mathrm{CO}_{2}(\mathrm{ppm})$ & Method $^{*}$ \\
\hline NOAA/ESRL & G2401 & CFKBDS2007 & $131-303$ & $360-390$ & $\# 1$ and \#2 \\
& G2401 & CFKBDS2008 & 301 & 385 & $\# 2$ \\
& G2302 & CKADS2027 & 177 & 450 & $\# 1$ \\
& G2401 & CFKBDS2059** & 129 & $380-550$ & $\# 2$ \\
Picarro, Inc. & G2302 & CKADS017 & $\sim 10^{6}$ & 0 & $\# 2$ \\
MPI-Mainz & G2302 & CKADS018 & $81-492$ & $365-470$ & $\# 2$ \\
MPI-Jena & G2401 & CFKBDS2003 & 213 & 395 & $\# 1$ and \#2 \\
& G2401 & CFKBDS2004 & $188-442$ & $390-440$ & $\# 1$ \\
\hline
\end{tabular}

${ }^{*}$ Refers to the water test method described in Sect. $2 .{ }^{* *}$ The only analyzer that is using the new fitting algorithm.

$\mathrm{CO}_{\text {wet }} / \mathrm{CO}_{\text {dry }}=1-\mathrm{H}_{2} \mathrm{O}$,

where $\mathrm{H}_{2} \mathrm{O}$ is the water vapor mole fraction.

In the case of CO measurements by the CRDS technique, there are a number of factors that complicate the correlation between $\mathrm{CO}_{\text {wet }}$ and $\mathrm{CO}_{\text {dry }}$ : (1) the linear term in Eq. (1) is not equal to -1 if water vapor is not accurately determined; (2) a nonlinear term exists as a result of pressure broadening (the mole fraction of $\mathrm{CO}$ is determined from the peak height of the absorption profile instead of the integrated spectral absorption area); (3) residual line interference remains due to imperfect quantifications of adjacent absorption lines of $\mathrm{CO}_{2}$ and $\mathrm{H}_{2} \mathrm{O}$. These effects can be compensated for by the following equation:

$\left(\mathrm{CO}_{\text {wet }}-\Delta \mathrm{CO}\right) / \mathrm{CO}_{\text {dry }}=\left(1+a^{\prime} \times \mathrm{H}_{2} \mathrm{O}_{\mathrm{pct}}+b^{\prime} \times \mathrm{H}_{2} \mathrm{O}_{\mathrm{pct}}^{2}\right)$,

where $\mathrm{CO}_{\text {wet }}$ is the mole fraction of $\mathrm{CO}$ in humid air. For compatibility between different analyzers of the same type, we consistently calculate $\mathrm{CO}_{\text {wet }}$ in $\mathrm{ppb}$ from the reported raw analyzer signal "peak84_raw" or "P84_RAW" as "peak84_raw" $\times 0.427 \times 1000$ or "P84_RAW" $\times 0.427 \times 1000(0.427$ is the default factory calibration factor). $\mathrm{CO}_{\mathrm{dry}}$ is the mole fraction of $\mathrm{CO}$ in dry air; $\Delta \mathrm{CO}$ is the line interference adjustment to account for the residuals in the line fits of adjacent absorption lines of $\mathrm{CO}_{2}$ and $\mathrm{H}_{2} \mathrm{O}$, and is a function of $\mathrm{CO}_{2}$ and $\mathrm{H}_{2} \mathrm{O}$ mole fractions, not of $\mathrm{CO}$ mole fraction; $a^{\prime}$ and $b^{\prime}$ are coefficients in the quadratic function to correct for the dilution and pressure-broadening effects and are given in $\%^{-1} ; \mathrm{H}_{2} \mathrm{O}_{\text {pct }}$ is one of the water vapor mole fraction measurements reported by the Picarro instrument (with the variable name " $\mathrm{H}_{2} \mathrm{O}_{-}$pct"), and is determined from the detection of the absorption lines of $\mathrm{H}_{2} \mathrm{O}$ that are adjacent to the absorption line of $\mathrm{CO}$, and is given in \%. Since $\mathrm{H}_{2} \mathrm{O}_{\text {pct }}$ directly affects the $\mathrm{CO}$ absorption line, it is appropriate to use measurements of these water vapor lines to correct all water vapor effects for $\mathrm{CO}$ measurements.

The CRDS analyzers mentioned above use the same spectroscopic fitting algorithms to derive the mole fractions of $\mathrm{CO}$ and $\mathrm{CO}_{2}$, and therefore the dilution and pressurebroadening effects for $\mathrm{CO}$ are expected to be similar to those for $\mathrm{CO}_{2}$. The corrections for these effects are a function of water vapor mole fractions, and are proportional to the mole fractions of $\mathrm{CO}$. On the other hand, the line interferences caused by the residuals in the quantifications of adjacent $\mathrm{CO}_{2}$ and $\mathrm{H}_{2} \mathrm{O}$ absorption lines are independent of the mole fractions of $\mathrm{CO}$ as they only affect the baseline of the $\mathrm{CO}$ absorption. Since the parameters associated with dilution and pressure broadening $\left(a^{\prime}\right.$ and $\left.b^{\prime}\right)$ and line interference $(\Delta \mathrm{CO})$ in Eq. (2) cannot be directly fit using measurements of $\mathrm{CO}_{\text {wet }}$ and known $\mathrm{CO}_{\text {dry }}$, we solve for these two effects separately based on water test data from laboratory experiments.

The water test data presented in this paper were obtained based on two different methods described in Rella et al. (2013). Method \#1 employs a dew point generator (LICOR model 610) or a micromodule (http://www.liqui-cel. $\mathrm{com} /$ product-information/micromodule.cfm) to humidify a gas stream from a cylinder. The advantage of this method is that mole fractions of $\mathrm{CO}$ in humidified gas are determined when the system has reached some equilibrium state at each humidity level. Method \#2 can be described as a water droplet test. In this method, a small amount $(0.2-0.8 \mathrm{~mL})$ of distilled (or deionized) water is injected into the inlet of the CRDS analyzer to humidify air from a cylinder. The water droplet added to the inlet line is held at the hydrophobic particulate filter of the analyzer, through which water can only pass in the form of water vapor. This method is easy to perform and provides water vapor ranging from 0 to $6 \%$, but the vapor amount changes rapidly. To obtain slowly changing water vapor mole fraction, a small amount of silica gel soaked with deionized or acidified water and housed inside a small flow through chamber has been used at NOAA/ESRL to humidify the gas stream. Water test data from a list of experiments are summarized in Table 1. The two methods have been employed at different times by different groups. We have performed water droplet tests to demonstrate that the $\mathrm{CO}$ mole fractions are not affected by silica gel or acidified water, where the humidified air was passed through a chemical dryer (magnesium perchlorate) and the dry mole fractions 

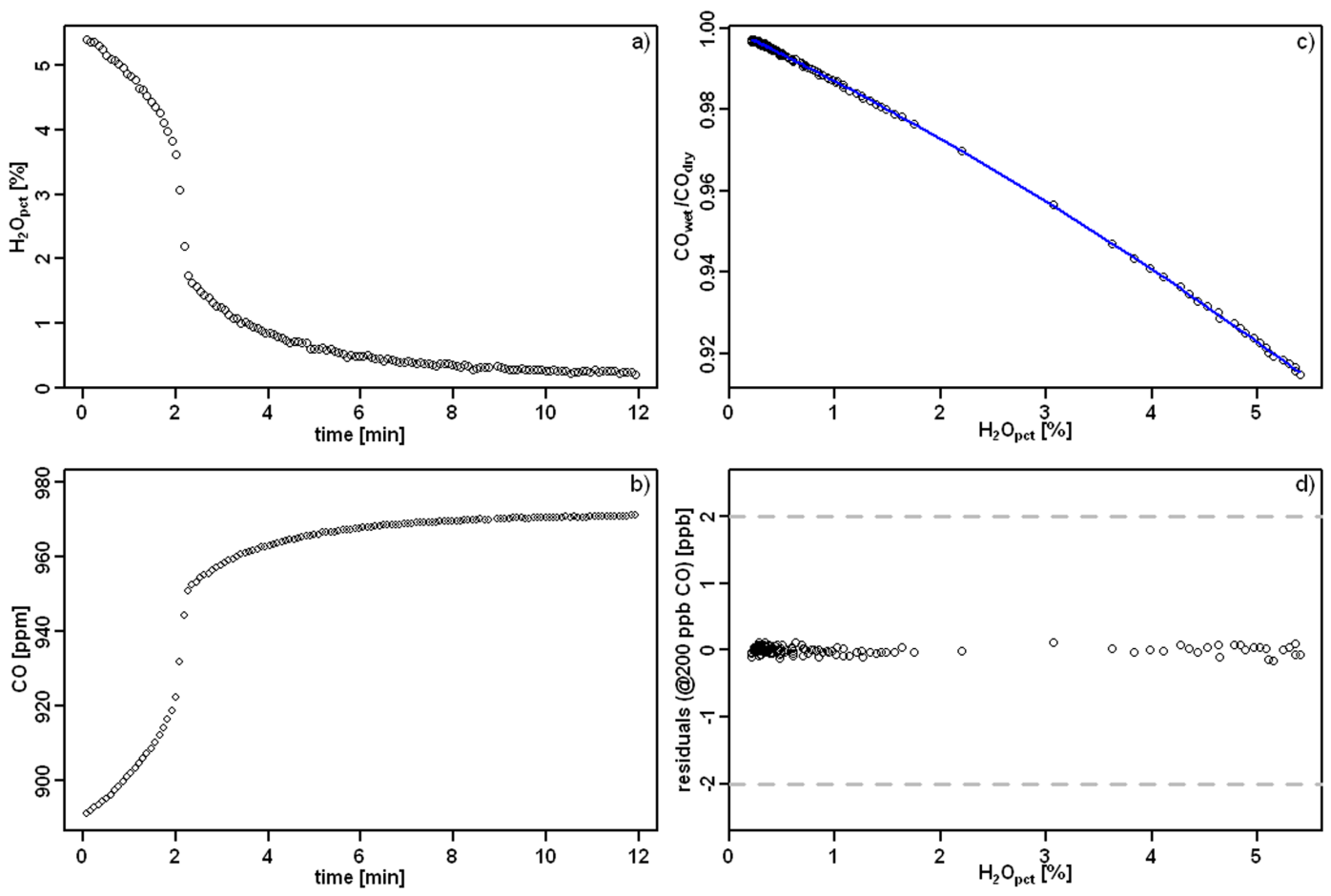

Fig. 2. Experimental data and analysis results during a water test using air with a high mole fraction of CO $\sim 1000 \mathrm{ppm}$ : (a) and (b) time series of $\mathrm{H}_{2} \mathrm{O}_{\text {pct }}$ and mole fractions of measured $\mathrm{CO}$ during the test, respectively; $\mathrm{x}$-axis is given in minutes relative to the start of the experiment. (c) Plots of $\mathrm{CO}_{\text {wet }} / \mathrm{CO}_{\text {dry }}$ vs. $\mathrm{H}_{2} \mathrm{O}_{\text {pct }}$ and a quadratic fit (curve in blue). (d) The black circles are residuals of the curve fit in (c) when applied to $200 \mathrm{ppb}$ dry mole fraction of $\mathrm{CO}$, with a standard deviation of $0.06 \mathrm{ppb}$; dashed lines indicate the compatibility goals set by the WMO for CO measurements.

of CO were then determined by a second CRDS analyzer. No significant variations/drifts in the dry mole fractions of $\mathrm{CO}$ were found (less than $1 \mathrm{ppb}$ CO on $30 \mathrm{~s}$ averaged data).

\subsection{Corrections for dilution and pressure-broadening effects}

At typical CO mole fractions found in the atmosphere (50$500 \mathrm{ppb}$ ), the effects of dilution and pressure broadening are of the same order of magnitude as the line interferences. Therefore, these two types of effects cannot be differentiated in one experiment with ambient levels of $\mathrm{CO}$. To minimize the effect of line interferences from $\mathrm{CO}_{2}$ and $\mathrm{H}_{2} \mathrm{O}$, a water test was performed at Picarro Inc. in August 2010 on a $\mathrm{CO}_{2} / \mathrm{CO} / \mathrm{H}_{2} \mathrm{O}$ analyzer (S/N: CKADS017) using cylinder air with a very high mole fraction of $\mathrm{CO}\left(\sim 10^{6} \mathrm{ppb}\right)$ and no $\mathrm{CO}_{2}$. The experiment was carried out under a fume hood, using the simple water droplet test (method \#2, with a heated filter) and water vapor mole fractions ranging from 0 to $6 \%$. In this case, the line interferences are negligible when compared to the influences by dilution and pressure broadening. The experimental data and analysis results are shown in Fig. 2. Both dilution and pressurebroadening effects can be accounted for using the quadratic function in Eq. (2) $(\Delta \mathrm{CO} \approx 0)$, and the derived coefficients $a^{\prime}=-1.24 \times 10^{-2} \%^{-1}$ and $b^{\prime}=-6.0 \times 10^{-4} \%^{-2}$. These two coefficients are very close to those for $\mathrm{CO}_{2}$ : $a=-1.20 \times 10^{-2} \%^{-1}$ and $b=-2.67 \times 10^{-4} \%^{-2}$ (Chen et al., 2010). The residuals of the quadratic fit applied to $200 \mathrm{ppb}$ dry mole fraction of $\mathrm{CO}$ are much smaller than the WMO-recommended compatibility of $\pm 2 \mathrm{ppb}$ for atmospheric $\mathrm{CO}$ measurements, with a standard deviation of $0.06 \mathrm{ppb}$ (Fig. 2d). Here we scale the $\mathrm{CO}$ residuals from the quadratic fit for the $1000 \mathrm{ppm} \mathrm{CO}$ test proportionally to the equivalent residuals for a $\mathrm{CO}$ mole fraction of $200 \mathrm{ppb}$. The dilution effect is proportional to the mole fractions of $\mathrm{CO}$, and the pressure-broadening effect is assumed to be proportional to the mole fractions of $\mathrm{CO}$ based on the fact that the coefficients $a^{\prime}$ and $b^{\prime}$ are close to those for $\mathrm{CO}_{2}$. Transferring the water correction coefficients for $\mathrm{CO}_{2}$ from one CRDS analyzer to another causes uncertainty on the order of $0.1 \mathrm{ppm}$ out of $400 \mathrm{ppm}$ for $\mathrm{CO}_{2}$ (Chen et al., 2010; Rella et al., 2013), which is at least one order of magnitude more accurate than needed for the transferability of $\mathrm{CO}$ water corrections for dilution and pressure broadening among different analyzers (with the WMO-recommended inter-laboratory compatibility goal of $2 \mathrm{ppb}$ for $\mathrm{CO}$ ). Furthermore, the total water vapor dilution and pressure-broadening effects for $\mathrm{CO}$ are relatively small ( $\sim 5 \mathrm{ppb}$ for $2 \%$ water vapor at a level of $200 \mathrm{ppb}$ CO) when compared to the line interference effect 

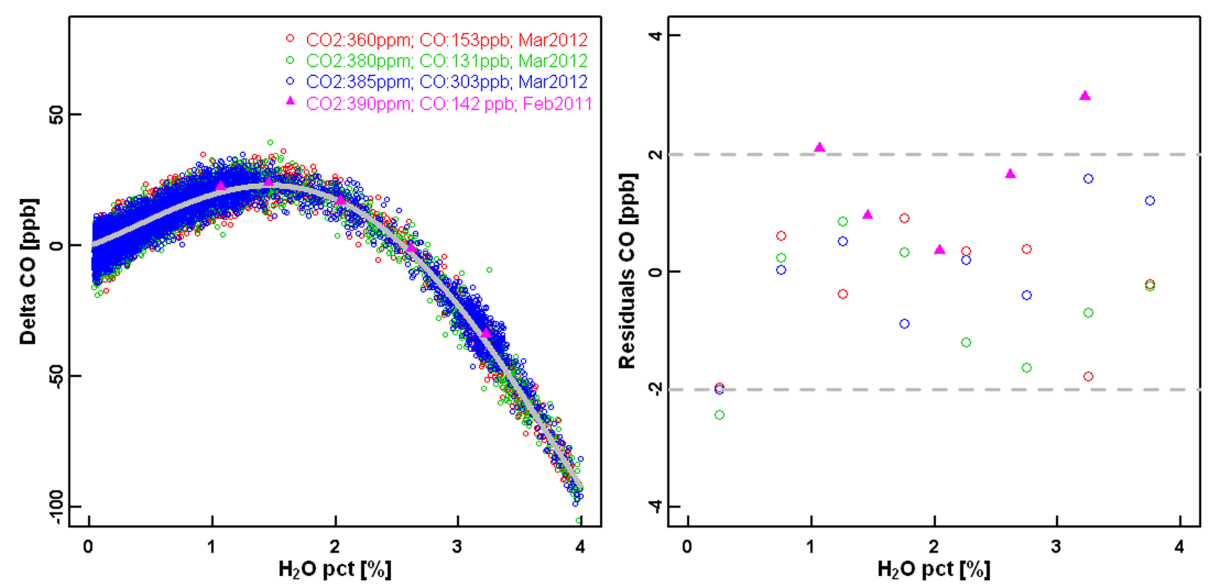

Fig. 3. Fourth-order fit of water droplet test data with $360-390 \mathrm{ppm} \mathrm{CO}_{2}$ (red, green, and blue), $\Delta \mathrm{CO}$ vs. $\mathrm{H}_{2} \mathrm{O}$ mole fractions for the range of $0-4 \%$. The experimental data were weighted based on the density of the measurements in the water vapor domain so that equal water vapor range contributed equally to the curve fit. The pink solid triangles are averaged values of $\Delta \mathrm{CO}$ obtained using water test method \#1 in February 2011, and cover a water vapor range of 1-3.2\% at discrete water vapor levels. The residuals from the fit for each water test, averaged over $0.5 \% \mathrm{H}_{2} \mathrm{O}$ intervals, are shown in the right figure.

(up to $\sim 20 \mathrm{ppb}$ for the range of $0-2 \%$ water vapor). Therefore, these coefficients can be assumed to be transferable to all CO measurements made by the same type of CRDS analyzer to account for dilution and pressure-broadening effects with insignificant transferability errors.

\subsection{Corrections for line interferences}

An additional correction to the derivation of $\mathrm{CO}_{\text {dry }}$ involves the line interferences caused by the residuals in the quantification of adjacent absorption lines of $\mathrm{CO}_{2}$ and $\mathrm{H}_{2} \mathrm{O}$; these are functions of $\mathrm{CO}_{2}$ and $\mathrm{H}_{2} \mathrm{O}$ mole fractions. To simplify the problem, we develop a function to correct for the line interferences caused by the residuals in the quantification of adjacent absorption lines of $\mathrm{H}_{2} \mathrm{O}$ only, and only estimate the influences from variations of $\mathrm{CO}_{2}$ mole fractions. For operation over a wider range of $\mathrm{CO}_{2}$ mole fractions, a more complete analysis is required. Five water tests have been performed on one $\mathrm{CO}_{2} / \mathrm{CH}_{4} / \mathrm{CO} / \mathrm{H}_{2} \mathrm{O}$ analyzer $(\mathrm{S} / \mathrm{N}$ CFKBDS2007) at the laboratory of NOAA/ESRL (see Table 1): one was done in February 2011 using a micromodule (method \#1), and four were completed in March 2012 using water droplets with different mole fractions of $\mathrm{CO}_{2}$ and $\mathrm{CO}$ (silica gel soaked with deionized water, method \#2).

We fit a fourth-order polynomial function (Eq. 3) to the data from three droplet tests with $360-390$ ppm $\mathrm{CO}_{2}$ in air using a weighted least squares method using the $\mathrm{R}$ software (one droplet test was rejected due to a significant difference between the dry mole fraction measurements of $\mathrm{CO}$ before and after the test, probably due to a leak), and the weights in the curve fit were calculated based on the density of the measurements in the water vapor domain so that equal water vapor range contributed equally to the curve fit:

$\Delta \mathrm{CO}=A \times \mathrm{H}_{2} \mathrm{O}_{\mathrm{pct}}+B \times \mathrm{H}_{2} \mathrm{O}_{\text {pct }}^{2}+C \times \mathrm{H}_{2} \mathrm{O}_{\text {pct }}^{3}+D \times \mathrm{H}_{2} \mathrm{O}_{\text {pct }}^{4}$.
$A, B, C$, and $D$ are coefficients of the polynomial fit, and $\triangle \mathrm{CO}$ is calculated as $\mathrm{CO}_{\text {wet }}-\mathrm{CO}_{\mathrm{dry}} \times\left(1+a^{\prime} \times\right.$ $\left.\mathrm{H}_{2} \mathrm{O}+b^{\prime} \times \mathrm{H}_{2} \mathrm{O}^{2}\right)$, with $a^{\prime}=-1.24 \times 10^{-2} \%^{-1}, \quad$ and $b^{\prime}=-6.0 \times 10^{-4} \%^{-2}$ from Sect. 2.1.

The fourth-order function was empirically chosen. We tried to fit these data with a series of polynomial functions from the second order to the fifth order, and found the residuals of those fits below the fourth order exhibited a clear dependence on water vapor (not shown). Besides this, the standard deviations of the residuals were 3.3, 2.3, 1.1, and $1.1 \mathrm{ppb}$ for the $2 \mathrm{nd}-5$ th order fits. It is important to note that the coefficients $A-D$ represent the water vapor bias in the $\mathrm{CO}$ measurement after the basic spectral model for water vapor has been removed from the raw spectral data. In other words, if the spectral model describing this spectral region were perfect, then these coefficients would be zero. The experimentally derived $\triangle \mathrm{CO}$ and the fourth-order polynomial fit are given in Fig. 3. The February 2011 test was not fit due to the lack of data below $1 \% \mathrm{H}_{2} \mathrm{O}$.

The derived coefficients of the weighted fourth-order polynomial fit are $A=16.628 \%^{-1}, \quad B=12.460 \%^{-2}$, $C=-10.692 \%^{-3}$, and $D=1.275 \%^{-4}$. The $\Delta \mathrm{CO}$ values from the experiment performed in February 2011 are plotted in the same figure. The $0.5 \%$ bin averaged residuals are mostly within $\pm 2 \mathrm{ppb}$, except for two points that are slightly greater than $2 \mathrm{ppb}$ for the four tests with $\mathrm{CO}_{2}$ ranging from 360-390 ppm. The lowest water vapor interval exhibits a bias of $\sim-2 \mathrm{ppb}$, which is caused by the inaccurate determination of dry $\mathrm{CO}$ values of the gases used in the experiments. Because we force the curve through zero, this would not lead to a systematic error in reported $\mathrm{CO}$ mole fractions at very low water vapor mole fractions. The noise of the CRDS CO measurements is mostly random, which has been shown in the Allan deviation plot by Zellweger 

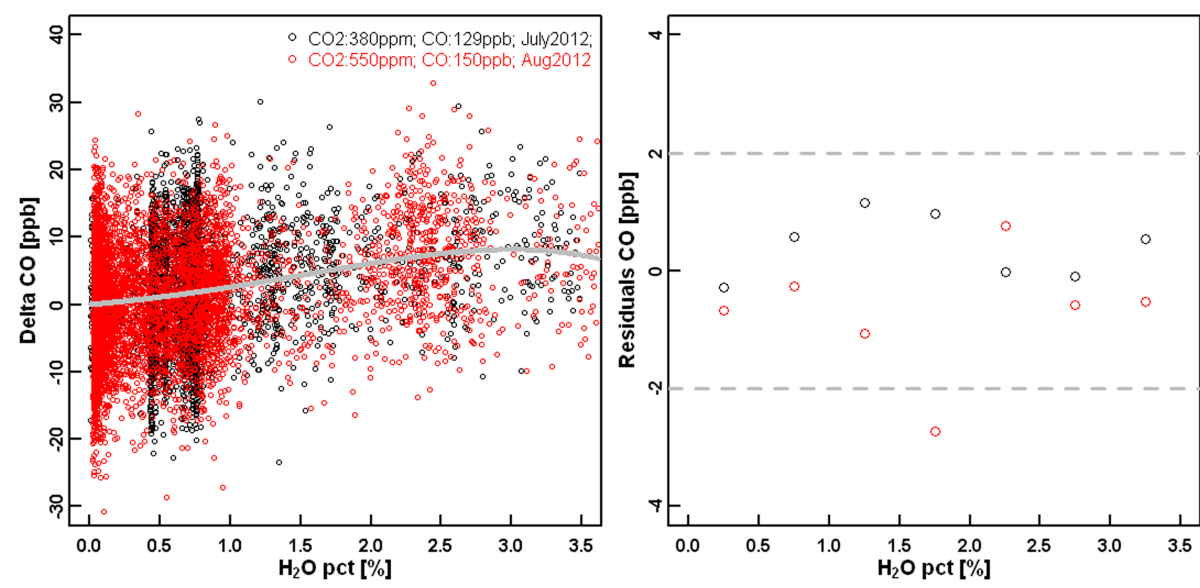

Fig. 4. Fourth-order fit of water droplet test data for analyzer with new fitting algorithm, $\Delta \mathrm{CO}$ vs. $\mathrm{H}_{2} \mathrm{O}$ mole fractions for the range of $0-3.5 \%$. The experimental data were weighted in the same way as for those presented in Fig. 3 . The residuals from the fit are shown in the right figure, and dashed lines indicate the compatibility goals set by the WMO for $\mathrm{CO}$ measurements. The residuals from the fit for each water test, averaged over $0.5 \% \mathrm{H}_{2} \mathrm{O}$ intervals, are shown in the right figure.

et al. (2012). Furthermore, there is no evidence of drift in the water correction functions from February 2011 to March 2012.

The tests cover $\mathrm{CO}$ mole fractions ranging from 131 to $303 \mathrm{ppb}, \mathrm{CO}_{2}$ mole fractions ranging from 360 to $390 \mathrm{ppm}$, and $\mathrm{H}_{2} \mathrm{O}$ mole fractions ranging from 0 to $4 \%$. The fact that all these data can be fit to one single function with small residuals demonstrates that this correction is independent of $\mathrm{CO}$ mole fractions for the range of $\mathrm{CO}_{2}$ from 360 to $390 \mathrm{ppm}$. An extensive characterization of the dependence of $\mathrm{CO}$ water corrections on $\mathrm{CO}_{2}$ abundance requires determination of a linear term in $\mathrm{CO}_{2}$ and a term that is linear in the product of $\mathrm{CO}_{2}$ and $\mathrm{H}_{2} \mathrm{O}$. We do not have enough test data to quantify these two terms from the water tests. However, we performed a water test using $550 \mathrm{ppm} \mathrm{CO}_{2}$ for a different CRDS analyzer and did not observe significant differences in the $\mathrm{CO}$ water corrections from what is determined from a water test using $380 \mathrm{ppm} \mathrm{CO}_{2}$ (see Sect. 2.3, Fig. 4). The dependence of $\mathrm{CO}$ measurements in dry air on $\mathrm{CO}_{2}$ is presented in Sect. 2.4. Note that the sizes of the third- and fourth-order terms are large at high water concentrations, and the correction factors can only be used for the tested water vapor range of $0-4 \%$. Extrapolating the polynomial curve to higher water vapor values will cause a large uncertainty.

\subsection{Corrections for line interferences for analyzers with a new fitting algorithm}

Since the beginning of 2012, a new line fitting algorithm has been applied by Picarro Inc. to the $\mathrm{CO}$ analyzers, which reduces the line interferences from water vapor on the $\mathrm{CO}$ measurements. We performed two water droplet tests (method \#2, 380 and $550 \mathrm{ppm} \mathrm{CO}_{2}$ ) at NOAA/ESRL on a $\mathrm{CO}_{2} / \mathrm{CH}_{4} / \mathrm{CO} / \mathrm{H}_{2} \mathrm{O}$ analyzer (CFKBDS2059) that uses the new fitting algorithm. Note that the corrections for water vapor dilution and pressure-broadening effects for $\mathrm{CO}$ have not been changed with the new fitting algorithm, and the coefficients obtained in Sect. 2.1 apply for instruments with the new fitting algorithm as well. The same fourth-order polynomial function was used to fit the data from the water test (see Fig. 4), and the derived coefficients are $A=2.032 \%^{-1}$, $B=1.821 \%^{-2}, C=-0.671 \%^{-3}$, and $D=0.048 \%^{-4}$. Compared to the corrections shown in Fig. 3, the magnitude of the correction has been significantly reduced, especially in the higher order terms. Note that no significant differences have been observed for the test data using $550 \mathrm{ppm} \mathrm{CO}_{2}$.

\subsection{Dependence of $\mathrm{CO}$ measurements on $\mathrm{CO}_{2}$ mole fractions}

A dependence of $\mathrm{CO}$ measurements on $\mathrm{CO}_{2}$ mole fractions is expected due to line interferences. To characterize the dependence, one experiment was performed on one $\mathrm{CO}_{2} / \mathrm{CH}_{4} / \mathrm{CO} / \mathrm{H}_{2} \mathrm{O}$ analyzer (S/N CFKBDS2007) at Picarro Inc. in January 2011, and the apparatus is shown in Fig. 5.

To start with, air from a low $\mathrm{CO}_{2}$ cylinder was provided to the CRDS analyzer after passing through a $\mathrm{CO}$ scrubber (Sofnocat 514), and then switched to air from a high $\mathrm{CO}_{2}$ cylinder. The Sofnocat responds very slowly to changes in $\mathrm{CO}_{2}$ (it was adsorbed on the Sofnocat substrate) so that a slow change in $\mathrm{CO}_{2}$ was obtained (Fig. 6a). The water level was about $0.4 \%$, and was stable throughout the measurement (Fig. 6b). The reading of raw $\mathrm{CO}$ was not close to zero due to the presence of water vapor (Fig. 6c). Water corrections were then applied based on Eq. (5) and the coefficients in Sects. 2.1 and 2.2 to derive dry $\mathrm{CO}$, which was indeed around zero (Fig. 6d). From a linear fit of dry $\mathrm{CO}$ to $\mathrm{CO}_{2}$, we derive a dependence of $\mathrm{CO}$ measurements of $-0.3 \mathrm{ppb} \mathrm{CO} / 100 \mathrm{ppm}$ $\mathrm{CO}_{2}$, and the $100 \mathrm{ppm}$ bin averaged residuals of the linear fit are smaller than $\pm 1 \mathrm{ppb}$ (Fig. 6e and f). 


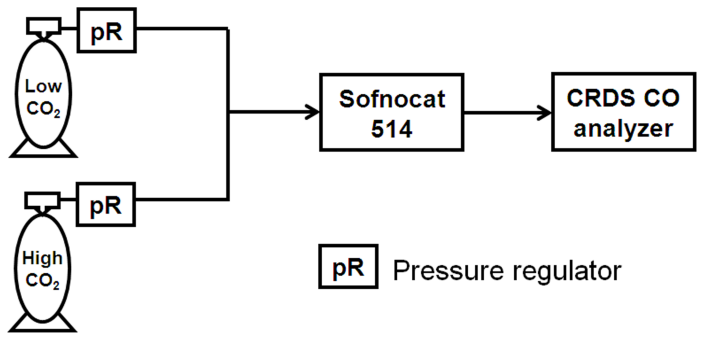

Fig. 5. Schematics of the $\mathrm{CO}_{2}$ dependence test.

Alternatively, the $\mathrm{CO}_{2}$ dependence can be derived from measurements of a series of $\mathrm{CO}$ standards with different $\mathrm{CO}_{2}$ mole fractions by fitting the following equation:

$\mathrm{CO}_{\text {cylinder }}=A^{\prime}+B^{\prime} \times \mathrm{CO}_{\text {raw }}+C^{\prime} \times \mathrm{CO}_{2}$.

Here $\mathrm{CO}_{\text {cylinder }}$ is the known $\mathrm{CO}$ mole fraction, $\mathrm{CO}_{\text {raw }}$ the measured mole fraction by a CRDS analyzer ("peak84 raw" $^{\prime} 0.427 \times \mathrm{i} 000$ ), and $\mathrm{CO}_{2}$ the $\mathrm{CO}_{2}$ mole fraction. To be able to determine the parameters $A^{\prime}, B^{\prime}$, and $C^{\prime}$ accurately, a large span of $\mathrm{CO}_{2}$ is required (our calibration data are not shown due to a narrow span of $\mathrm{CO}_{2}$ ).

\subsection{Application of corrections for CO measurements}

Combining the corrections for dilution and pressure broadening and for line interferences, Eqs. (2)-(3), the corrected $\mathrm{CO}$ values can be expressed as

$\mathrm{CO}_{\text {corrected }}=\frac{\mathrm{CO}_{\text {wet }}-\left(A \times \mathrm{H}_{2} \mathrm{O}_{\text {pct }}+B \times \mathrm{H}_{2} \mathrm{O}_{\mathrm{pct}}^{2}+C \times \mathrm{H}_{2} \mathrm{O}_{\mathrm{pct}}^{3}+D \times \mathrm{H}_{2} \mathrm{O}_{\mathrm{pct}}^{4}\right)}{1+a^{\prime} \times \mathrm{H}_{2} \mathrm{O}_{\mathrm{pct}}+b^{\prime} \times \mathrm{H}_{2} \mathrm{O}_{\mathrm{pct}}^{2}}$

The coefficients $a^{\prime}=-1.24 \times 10^{-2} \%^{-1}$ and $b^{\prime}=-6.0 \times$ $10^{-4} \%^{-2}$ can be used for different analyzers, whereas coefficients $A, B, C$, and $D$ need to be determined from instrument-specific water tests (see Sect. 3). Note that we do not include any $\mathrm{CO}_{2}$ dependence in the correction function because it is determined to be small for $\mathrm{CO}_{2}$ mole fractions ranging from 360-390 ppm.

The standard deviations of the $\mathrm{CO}$ measurements made by the CRDS analyzers at the reported frequency $(\sim 0.5 \mathrm{~Hz})$ are in the range of 4-17 ppb. For $\mathrm{H}_{2} \mathrm{O}_{\mathrm{pct}}$ the standard deviations increase with water vapor levels, and are smaller than $100 \mathrm{ppm}$ for up to $3.6 \%$ water vapor. The uncertainty of the $\mathrm{CO}$ water corrections due to the precision of $\mathrm{H}_{2} \mathrm{O}_{\text {pct }}$ at the reported frequency is calculated based on Eq. (5) and is less than $0.5 \mathrm{ppb}$ for up to $3.6 \%$ water vapor, which is a smaller effect when compared to the uncertainty in the determined water vapor corrections for $\mathrm{CO}$.

\section{Transferability of water corrections across different analyzers}

When using the water corrections given in Eq. (4), it is important to understand how consistent they are from one
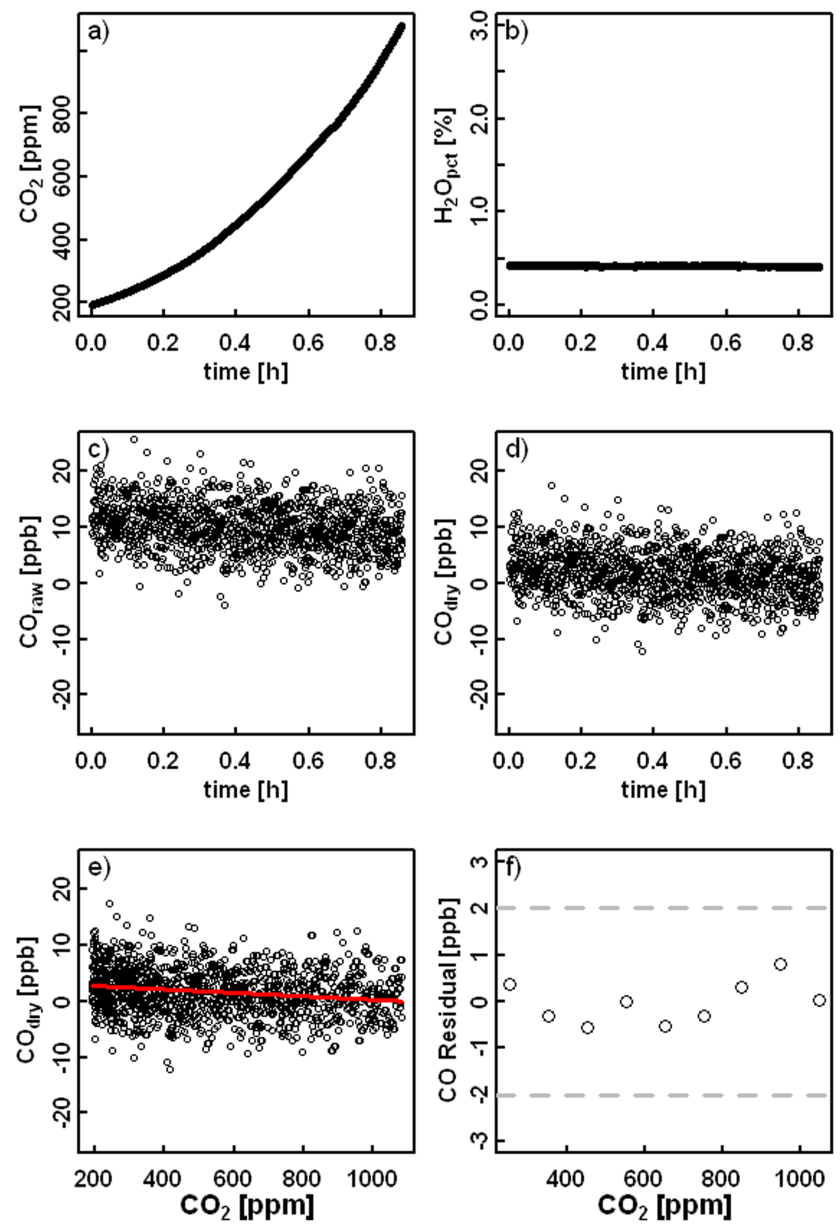

Fig. 6. Experimental data of a $\mathrm{CO}_{2}$ dependence test: (a) the slow change in $\mathrm{CO}_{2}$ over time; (b) the time series of water vapor; (c) the time series of raw $\mathrm{CO}$; (d) the time series of water-corrected dry $\mathrm{CO}$; (e) dry $\mathrm{CO}$ vs. $\mathrm{CO}_{2}$, and a linear fit shown by the red line; (f) the $100 \mathrm{ppm}$ bin-averaged residuals of the linear fit. Dashed lines indicate the compatibility goals set by the WMO for $\mathrm{CO}$ measurements.

instrument to the other. In total, water tests have been performed on five analyzers with the old fitting algorithm in groups from NOAA/ESRL (CFKBDS2008 and CKADS2027), MPI-Jena (CFKBDS2003 and CKADS2004), and MPI-Mainz (CKADS018) using method \#1 and/or method \#2 (see Table 1). The differences between the corrected $\mathrm{CO}$ values based on the coefficients derived in Sect. 2.2 and the measured dry mole fraction of $\mathrm{CO}$ for each test and analyzer are shown in Fig. 7. Note that several test results may have been averaged for each individual analyzer. The results clearly show that each analyzer requires instrument-specific water corrections (i.e., coefficients $A, B$, $C$, and $D$ ) to meet the WMO-recommended compatibility of $\pm 2 \mathrm{ppb}$. The variations in the $\mathrm{CO}$ correction function between analyzers capture the small differences in the spectrograms delivered by each instrument, due to tiny differences 


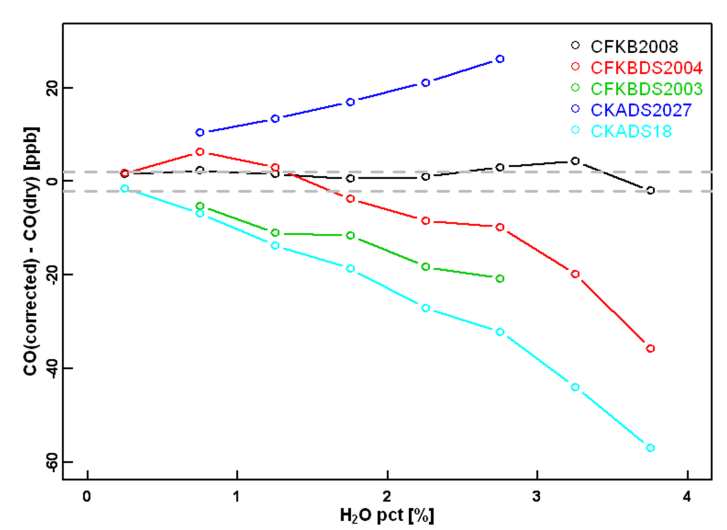

Fig. 7. Differences of corrected wet measurements using the coefficients $\left(A=16.628 \%^{-1}, B=12.460 \%^{-2}, C=-10.692 \%^{-3}\right.$, $D=1.275 \%^{-4}$ ) derived in Sect. 2 for CFKBDS2007 and dry values for water tests on each analyzer. Dashed lines indicate the compatibility goals set by the WMO for CO measurements.

between the reported wavelengths, absorbances, temperature, or pressure.

\section{Field validation}

The CRDS analyzer tested in Sect. 2 (CFKBDS2007) was flown without a drying system on board an aircraft in Alaska from April to November 2011, and from April 2012 until the present. A detailed description of the field deployment is given by Karion et al. (2013). A total of 12 flights were performed in 2011, and each flight took $\sim 8 \mathrm{~h}$, during which 24 flasks were sampled. In-flight calibrations were made by providing air from three cylinders to the CRDS analyzer every $30 \mathrm{~min}$. The flasks were analyzed at NOAA/ESRL, with an uncertainty of $2 \mathrm{ppb}$ (Novelli et al., 2003). The in situ $\mathrm{CO}$ measurements were integrated using weighting functions that accounted for observed atmospheric variability during the flask sampling period (Chen et al., 2012). To accurately represent the weighting functions, knowing the times when the pressurizing process started and ended is critical. Since only the times when the pressurizing process ended were recorded, the times when the pressurizing process started were estimated based on the ambient pressure and the time it takes to fill a flask on the ground. The comparison of integrated in situ measurements with flask measurements of $\mathrm{CO}$ during all flights shows a mean bias of $-0.6 \mathrm{ppb}$ and a standard deviation of the differences of $2.8 \mathrm{ppb}$, which is better than the WMO-recommended inter-laboratory compatibility of $\pm 2 \mathrm{ppb}$. Further, no significant linear trend of the differences between in situ and flask measurements on any of the variables (day, $\mathrm{H}_{2} \mathrm{O}_{\text {pct }}, \mathrm{CO}_{2}, \mathrm{CO}, \mathrm{CH}_{4}$, and ambient pressure) has been found (the calculated linear coefficients are not statistically different from 0 ), partially due to the relatively large scatter in the differences between in situ and flask measurements (Fig. 8).
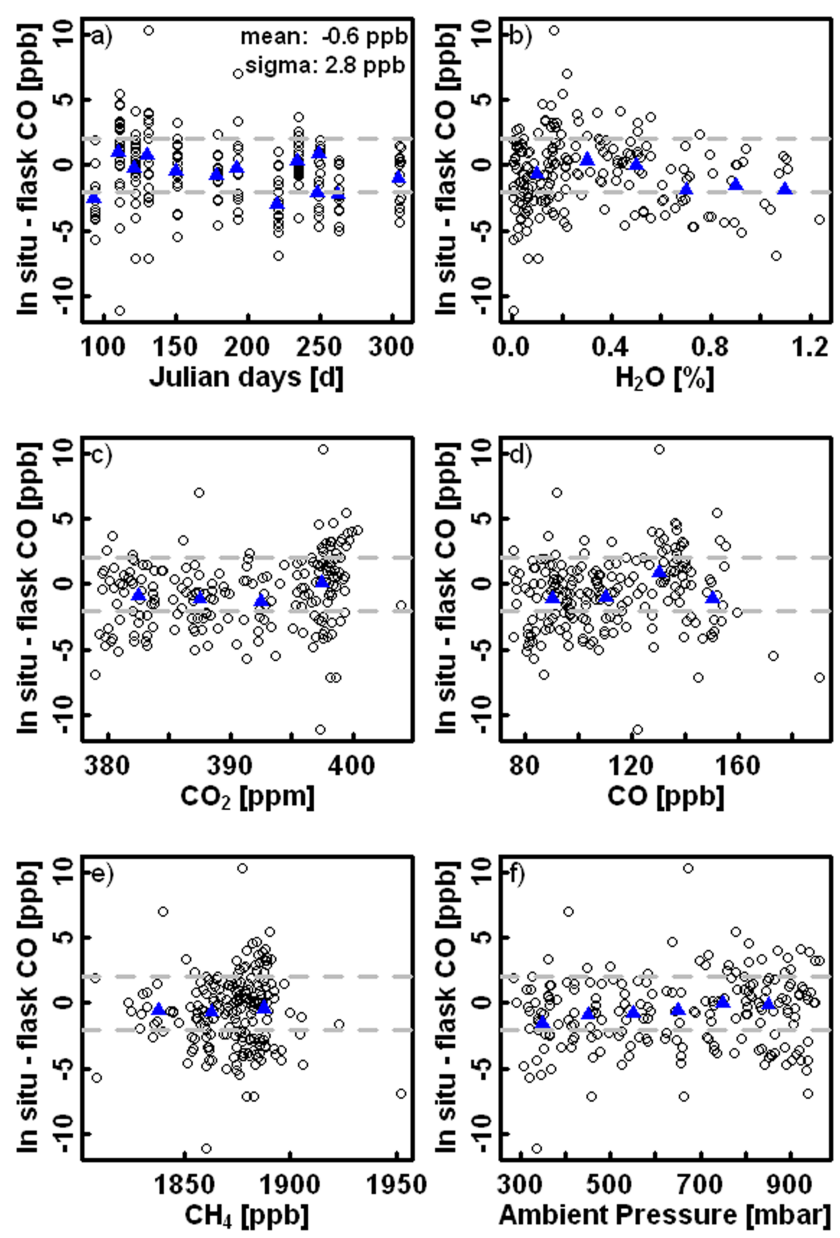

Fig. 8. Comparisons of in situ and flask measurements of $\mathrm{CO}$ made by NOAA/ESRL on board an aircraft in Alaska in 2011. (a) The time series of the differences between integrated in situ measurements and flask measurements, with the mean values of the binned biases in time (per flight); (b)-(f) the differences between in situ measurements and flask measurements plotted as a function of $\mathrm{H}_{2} \mathrm{O}, \mathrm{CO}_{2}, \mathrm{CO}, \mathrm{CH}_{4}$, and ambient pressure, with the mean values of the binned biases in $\mathrm{H}_{2} \mathrm{O}$ (0.2\% bin), $\mathrm{CO}_{2}$ ( 5 ppm bin), $\mathrm{CO}$ (20 ppb bin), $\mathrm{CH}_{4},(25 \mathrm{ppb}$ bin) and ambient pressure (100 mbar bin) bands, shown in blue triangles. The WMO-recommended compatibility of $\pm 2 \mathrm{ppb}$ is shown in each plot in grey dashed lines.

\section{Discussion and conclusion}

Accurate measurements of carbon monoxide (CO) in humid air have been made using the cavity ring-down spectroscopy (CRDS) technique. The measurements of $\mathrm{CO}$ mole fractions are determined from the strength of its spectral absorption in the near-infrared region $(\sim 1.57 \mu \mathrm{m})$ after removing interferences from adjacent carbon dioxide $\left(\mathrm{CO}_{2}\right)$ and water vapor $\left(\mathrm{H}_{2} \mathrm{O}\right)$ absorption lines. To obtain dry mole fractions of $\mathrm{CO}$ without a need to dry the ambient air, laboratory experiments have been carried out to derive the water correction functions for $\mathrm{CO}$. These water correction functions account for the 
dilution and pressure-broadening effects as well as line interferences from adjacent $\mathrm{CO}_{2}$ and $\mathrm{H}_{2} \mathrm{O}$ absorption lines for $\mathrm{CO}_{2}$ mole fractions between 360-390 ppm and for reported $\mathrm{H}_{2} \mathrm{O}$ mole fractions between $0-4 \%$, and are independent of $\mathrm{CO}$ mole fractions. We determined a dependence of $\mathrm{CO}$ measurements on $\mathrm{CO}_{2}$ mole fractions of $-0.3 \mathrm{ppb} \mathrm{CO} / 100 \mathrm{ppm}$ $\mathrm{CO}_{2}$. This result quantifies the potential errors of $\mathrm{CO}$ measurements under varying $\mathrm{CO}_{2}$ mole fractions. For measurements of $\mathrm{CO}$ aboard aircraft or at a background observational site, the dependence seems to be rather small, since variations of $\mathrm{CO}_{2}$ larger than $100 \mathrm{ppm} \mathrm{CO}_{2}$ are rarely seen (corresponding to a bias of $\mathrm{CO} \pm 0.3 \mathrm{ppb}$ ). For the cases when significant $\mathrm{CO}_{2}$ variations are possible (e.g., exhaust measurements and soil chamber experiments), the dependence of $\mathrm{CO}$ measurements on mole fractions of $\mathrm{CO}_{2}$ needs to be better characterized.

Unlike the good transferability of the water correction coefficients for $\mathrm{CO}_{2}$ and $\mathrm{CH}_{4}$ among different CRDS analyzers (Rella et al., 2013), comparisons of water correction functions for $\mathrm{CO}$ from five different analyzers of the same type show significant differences, making it necessary to perform instrument-specific water tests for each individual analyzer. The magnitude of the water corrections has been significantly reduced by employing a new fitting algorithm (in Picarro CRDS CO analyzers newer than early 2012). Further tests need to be done to determine if the transferability of the water corrections for analyzers using the new fitting algorithm has been improved. From our limited experience, significant drift has not been observed in the water corrections for one CRDS analyzer (CFKBDS2007) over a period of one year. Based on these laboratory studies showing the sensitivity of the water correction to $\mathrm{CO}_{2}$ mole fraction and the analyzer to analyzer variability, it is recommended that fits be made to each analyzer periodically with standard gas concentrations that closely resemble both the span of $\mathrm{CO}_{2}$ and $\mathrm{CO}$ that will be observed. This study applies to the CRDS instruments manufactured by Picarro Inc. that determine the CO mole fractions of air sample in a pressure- $(\sim 186 \mathrm{mbar})$ and temperature- $\left(\sim 45^{\circ} \mathrm{C}\right)$ controlled cavity based on light absorption in the near-infrared region $(\sim 1.57 \mu \mathrm{m})$. CRDS instruments operated under different conditions or based on absorption at a different wavelength would need to be independently tested to see if the same or similar conclusions apply.

The CRDS analyzer was flown on an aircraft in Alaska from April to October in 2011, and the accuracy of the $\mathrm{CO}$ measurements by the CRDS analyzer has been validated against discrete NOAA/ESRL flask sample measurements made on board the same aircraft, with a mean difference between integrated in situ and flask measurements of $-0.6 \mathrm{ppb}$ and a standard deviation of $2.8 \mathrm{ppb}$. No significant linear trend of the differences between in situ and flask measurements could be detected, partly because the noise in the differences is relatively large. Direct comparisons of in situ measurements of $\mathrm{CO}$ by two or more side-by-side analyzers, as already investigated by Zellweger et al. (2012), could potentially discover or exclude issues that influence the accuracy of the $\mathrm{CO}$ measurements by the CRDS technique.

Although the precision of the $\mathrm{CO}$ measurements by the CRDS technique on a short-time period is not as high as other available techniques, such as QCL and ICOS, it is possible to make accurate measurements of $\mathrm{CO}$ using this technique without drying the air if measurements over a sufficiently long period can be integrated and calibrated against standards. The CRDS analyzer does not need frequent calibration (Winderlich et al., 2010; Karion et al., 2013; Richardson et al., 2012) or a drying system, and could be an accurate and low-maintenance instrument useful for monitoring the atmospheric mole fractions of $\mathrm{CO}$.

Acknowledgements. We would like to thank Pat Lang, Paul Novelli, Andrew Crotwell, Doug Guenther, Sonja Wolter, Jack Higgs, Duane Kitzis, John Kofler, and Arlyn Andrews at NOAA/ESRL Global Monitoring Division for supporting our work. This work was in part supported by the German Max Planck Society.

Edited by: A. C. Manning

\section{References}

Andreae, M. O. and Merlet, P.: Emission of trace gases and aerosols from biomass burning, Global Biogeochem. Cy., 15, 955-966, doi:10.1029/2000gb001382, 2001.

Chen, H., Winderlich, J., Gerbig, C., Hoefer, A., Rella, C. W., Crosson, E. R., Van Pelt, A. D., Steinbach, J., Kolle, O., Beck, V., Daube, B. C., Gottlieb, E. W., Chow, V. Y., Santoni, G. W., and Wofsy, S. C.: High-accuracy continuous airborne measurements of greenhouse gases $\left(\mathrm{CO}_{2}\right.$ and $\left.\mathrm{CH}_{4}\right)$ using the cavity ringdown spectroscopy (CRDS) technique, Atmos. Meas. Tech., 3, 375-386, doi:10.5194/amt-3-375-2010, 2010.

Chen, H., Winderlich, J., Gerbig, C., Katrynski, K., Jordan, A., and Heimann, M.: Validation of routine continuous airborne CO2 observations near the Bialystok Tall Tower, Atmos. Meas. Tech., 5, 873-889, doi:10.5194/amt-5-873-2012, 2012.

Crosson, E. R.: A cavity ring-down analyzer for measuring atmospheric levels of methane, carbon dioxide, and water vapor, Appl. Phys. B, 92, 403-408, 2008.

Dickerson, R. R. and Delany, A. C.: Modification of a commercial gas filter correlation $\mathrm{CO}$ detector for enhanced sensitivity, J. Atmos. Ocean. Tech., 5, 424-431, 1988.

Ehhalt, D. H. and Rohrer, F.: The tropospheric cycle of $\mathrm{H}_{2}$ : a critical review, Tellus B, 61, 500-535, doi:10.1111/j.16000889.2009.00416.x, 2009.

Gerbig, C., Schmitgen, S., Kley, D., Volz-Thomas, A., Dewey, K., and Haaks, D.: An improved fast-response vacuum-UV resonance fluorescence CO instrument, J. Geophys. Res.-Atmos., 104, 1699-1704, 1999.

Griffith, D. W. T., Deutscher, N. M., Caldow, C., Kettlewell, G., Riggenbach, M., and Hammer, S.: A Fourier transform infrared trace gas and isotope analyser for atmospheric applications, Atmos. Meas. Tech., 5, 2481-2498, doi:10.5194/amt-5-2481-2012, 2012. 
Karion, A., Sweeney, C., Wolter, S., Newberger, T., Chen, H., Andrews, A., Kofler, J., Neff, D., and Tans, P.: Long-term greenhouse gas measurements from aircraft, Atmos. Meas. Tech., 6, 511-526, doi:10.5194/amt-6-511-2013, 2013.

Levin, I. and Karstens, U.: Inferring high-resolution fossil fuel $\mathrm{CO}_{2}$ records at continental sites from combined $\left(\mathrm{CO}_{2}\right)-\mathrm{C}-14$ and $\mathrm{CO}$ observations, Tellus B, 59, 245-250, 2007.

Logan, J. A., Prather, M. J., Wofsy, S. C., and McElroy, M. B.: Tropospheric Chemistry - a global perspective, J. Geophys. Res.Oceans, 86, 7210-7254, doi:10.1029/JC086iC08p07210, 1981.

McManus, J. B., Shorter, J. H., Nelson, D. D., Zahniser, M. S., Glenn, D. E., and McGovern, R. M.: Pulsed quantum cascade laser instrument with compact design for rapid, high sensitivity measurements of trace gases in air, Appl. Phys. B, 92, 387-392, 2008.

Nara, H., Tanimoto, H., Tohjima, Y., Mukai, H., Nojiri, Y., Katsumata, K., and Rella, C. W.: Effect of air composition $\left(\mathrm{N}_{2}, \mathrm{O}_{2}, \mathrm{Ar}\right.$, and $\left.\mathrm{H}_{2} \mathrm{O}\right)$ on $\mathrm{CO}_{2}$ and $\mathrm{CH}_{4}$ measurement by wavelength-scanned cavity ring-down spectroscopy: calibration and measurement strategy, Atmos. Meas. Tech., 5, 2689-2701, doi:10.5194/amt-5-2689-2012, 2012.

Novelli, P. C.: CO in the atmosphere: measurement techniques and related issues, Chemosphere - Global Change Sci., 1, 115-126, 1999.

Novelli, P. C., Masarie, K. A., Lang, P. M., Hall, B. D., Myers, R. C., and Elkins, J. W.: Reanalysis of tropospheric CO trends: Effects of the 1997-1998 wildfires, J. Geophys. Res.-Atmos., 108, 4464, doi:10.1029/2002jd003031, 2003.

O'Keefe, A.: Integrated cavity output analysis of ultra-weak absorption, Chem. Phys. Lett., 293, 331-336, doi:10.1016/S00092614(98)00785-4, 1998.

Rella, C. W., Chen, H., Andrews, A. E., Filges, A., Gerbig, C., Hatakka, J., Karion, A., Miles, N. L., Richardson, S. J., Steinbacher, M., Sweeney, C., Wastine, B., and Zellweger, C.: High accuracy measurements of dry mole fractions of carbon dioxide and methane in humid air, Atmos. Meas. Tech., 6, 837-860, doi:10.5194/amt-6-837-2013, 2013.
Richardson, S. J., Miles, N. L., Davis, K. J., Crosson, E. R., Rella, C. W., and Andrews, A. E.: Field Testing of Cavity Ring-Down Spectroscopy Analyzers Measuring Carbon Dioxide and Water Vapor, J. Atmos. Ocean. Tech., 29, 397-406, doi:10.1175/jtechd-11-00063.1, 2012.

Sachse, G. W., Hill, G. F., Wade, L. O., and Perry, M. G.: Fastresponse, high-precision carbon-monoxide sensor using a tunable diode-laser absorption technique, J. Geophys. Res.-Atmos., 92, 2071-2081, doi:10.1029/JD092iD02p02071, 1987.

Turnbull, J., Rayner, P., Miller, J., Naegler, T., Ciais, P., and Cozic, A.: On the use of $\left(\mathrm{CO}_{2}\right)-\mathrm{C}-14$ as a tracer for fossil fuel $\mathrm{CO}_{2}$ : Quantifying uncertainties using an atmospheric transport model, J. Geophys. Res.-Atmos., 114, D22302, doi:10.1029/2009JD012308, 2009.

Varghese, P. L. and Hanson, R. K.: Collisional Narrowing Effects on Spectral-Line Shapes Measured at High-Resolution, Appl. Optics, 23, 2376-2385, 1984.

Winderlich, J., Chen, H., Gerbig, C., Seifert, T., Kolle, O., Lavric, J. V., Kaiser, C., Höfer, A., and Heimann, M.: Continuous lowmaintenance $\mathrm{CO}_{2} / \mathrm{CH}_{4} / \mathrm{H}_{2} \mathrm{O}$ measurements at the Zotino Tall Tower Observatory (ZOTTO) in Central Siberia, Atmos. Meas. Tech., 3, 1113-1128, doi:10.5194/amt-3-1113-2010, 2010.

Zellweger, C., Hüglin, C., Klausen, J., Steinbacher, M., Vollmer, M., and Buchmann, B.: Inter-comparison of four different carbon monoxide measurement techniques and evaluation of the long-term carbon monoxide time series of Jungfraujoch, Atmos. Chem. Phys., 9, 3491-3503, doi:10.5194/acp-9-3491-2009, 2009.

Zellweger, C., Steinbacher, M., and Buchmann, B.: Evaluation of new laser spectrometer techniques for in-situ carbon monoxide measurements, Atmos. Meas. Tech., 5, 2555-2567, doi:10.5194/amt-5-2555-2012, 2012. 